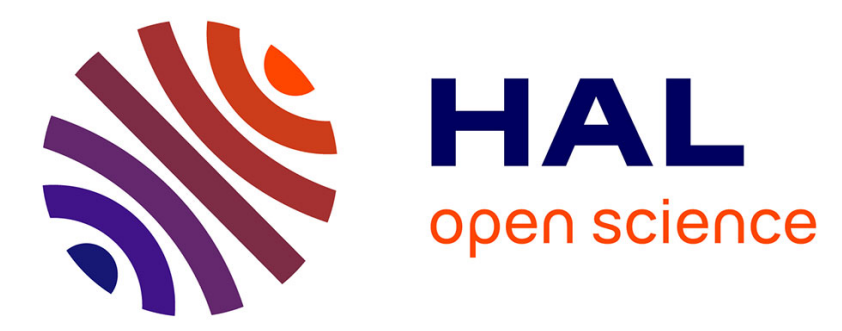

\title{
Tissue remodelling in breast cancer: human mast cell tryptase as an initiator of myofibroblast differentiation
}

Anita Mangia, Andrea Malfettone, Roberta Rossi, Angelo Paradiso, Girolamo Ranieri, Giovanni Simone, Leonardo Resta

\section{- To cite this version:}

Anita Mangia, Andrea Malfettone, Roberta Rossi, Angelo Paradiso, Girolamo Ranieri, et al.. Tissue remodelling in breast cancer: human mast cell tryptase as an initiator of myofibroblast differentiation. Histopathology, 2011, 58 (7), pp.1096. 10.1111/j.1365-2559.2011.03842.x . hal-00655186

\section{HAL Id: hal-00655186 \\ https://hal.science/hal-00655186}

Submitted on 27 Dec 2011

HAL is a multi-disciplinary open access archive for the deposit and dissemination of scientific research documents, whether they are published or not. The documents may come from teaching and research institutions in France or abroad, or from public or private research centers.
L'archive ouverte pluridisciplinaire HAL, est destinée au dépôt et à la diffusion de documents scientifiques de niveau recherche, publiés ou non, émanant des établissements d'enseignement et de recherche français ou étrangers, des laboratoires publics ou privés. 


\section{Histopathology}

\section{Tissue remodelling in breast cancer: human mast cell tryptase as an initiator of myofibroblast differentiation}

\begin{tabular}{|c|c|}
\hline Journal: & Histopathology \\
\hline Manuscript ID: & HISTOP-05-10-0263.R1 \\
\hline Wiley - Manuscript type: & Original Article \\
\hline $\begin{array}{r}\text { Date Submitted by the } \\
\text { Author: }\end{array}$ & 07-Sep-2010 \\
\hline Complete List of Authors: & $\begin{array}{l}\text { Mangia, Anita; National Cancer Centre "Giovanni Paolo II", Clinical } \\
\text { Experimental Oncology Laboratory } \\
\text { Malfettone, Andrea; National Cancer Centre "Giovanni Paolo II", } \\
\text { Clinical Experimental Oncology Laboratory } \\
\text { Rossi, Roberta; University of Bari, Department of Pathology } \\
\text { Paradiso, Angelo; National Cancer Centre "Giovanni Paolo II", } \\
\text { Clinical Experimental Oncology Laboratory } \\
\text { Ranieri, Girolamo; National Cancer Centre "Giovanni Paolo II, Unit } \\
\text { of Interventional Radiology } \\
\text { Simone, Giovanni; National Cancer Centre "Giovanni Paolo II", } \\
\text { Department of Pathology } \\
\text { Resta, Leonardo; University of Bari, Department of Pathology }\end{array}$ \\
\hline Keywords: & $\begin{array}{l}\text { breast cancer, a-SMA-positive myofibroblasts, toluidine blue- } \\
\text { positive mast cells, tryptase-positive mast cells }\end{array}$ \\
\hline
\end{tabular}

\section{SCHOLARONE ${ }^{\text {m }}$ Manuscripts}


Tissue remodelling in breast cancer: human mast cell tryptase as an initiator of myofibroblast differentiation

Anita Mangia ${ }^{1}$, Andrea Malfettone ${ }^{1}$, Roberta Rossi ${ }^{3}$, Angelo Paradiso ${ }^{1}$, Girolamo Ranieri ${ }^{4}$, Giovanni Simone $^{2}$ and Leonardo Resta ${ }^{3}$

${ }^{1}$ Clinical Experimental Oncology Laboratory, National Cancer Centre “Giovanni Paolo II”, Bari, Italy.

${ }^{2}$ Department of Pathology, National Cancer Centre "Giovanni Paolo II”, Bari, Italy.

${ }^{3}$ Department of Pathology, University of Bari, Bari, Italy.

${ }^{4}$ Unit of Interventional Radiology, National Cancer Centre "Giovanni Paolo II”, Bari, Italy.

Address for correspondence: Dr Anita Mangia, Clinical Experimental Oncology Laboratory, National Cancer Centre “Giovanni Paolo II”, Via Hahnemann 10, 70126 Bari, Italy. Telephone: 00390805555561. Fax: 0039 0805555537. E-mail: a.mangia@oncologico.bari.it

\section{Short running title: MAST CELL AS INITIATOR OF MYOFIBROBLAST}

Keywords: breast cancer, $\alpha$-SMA-positive myofibroblasts, toluidine blue, tryptase-positive mast cells Abbreviations: ECM, extra-cellular matrix; $\alpha$-SMA, $\alpha$-smooth-muscle actin; MCs, mast cells; MCs-TB, toluidine blue stained-mast cells; MCs-Try, tryptase immunolabeled-mast cells; T, primary tumor; PT, peri-tumoral tissue contiguous to tumor; NT, distant non-tumoral tissue; IDC-NOS, invasive ductal carcinoma-not otherwise specified; ILC, invasive lobular carcinoma; ICC, invasive cribriform carcinoma; CIS, carcinoma in situ; ER, estrogen receptor; PgR, progesterone receptor; PBS, phosphate-buffered saline. 


\section{Abstract}

Aims: Cancerogenesis is characterized by increase of differentiated myofibroblasts. Mast cells (MCs) exert powerful effects on fibroblasts through a variety of mediators. We investigated $\alpha-\mathrm{SMA}^{+}$and CD34 ${ }^{+}$fibroblasts, density of toluidine blue-stained (MCs-TB) and tryptase-immunolabeled MCs (MCsTry) in 30 primary breast tumors.

Methods and results: tumor (T), peri-tumoral (PT) and non-tumoral (NT) tissues were studied by immunohistochemistry and electron microscopy.

MCs-TB and MCs-Try increased gradually from NT, to PT and T and the comparison between the three compartments varied significantly. Degranulated MCs were present more significantly in NT and in adjacent PT than T.

Transition between NT, PT and T was marked by increasing $\alpha-\mathrm{SMA}^{+}$fibroblasts and slow disappearance of CD $34^{+}$stromal cells.

In NT, CD $34^{+}$fibroblasts correlated to low density both of MCs-TB and intact MCs-Try ( $\mathrm{p}=0.0346$ and $\mathrm{p}=0.0409$, respectively). In $\mathrm{T}$, the few preserved $\mathrm{CD} 34^{+}$fibroblasts were associated with low-density degranulated MCs-Try $(\mathrm{p}=0.0173)$.

The $\alpha$-SMA ${ }^{+}$fibroblasts correlated with high-density of intact MCs-Try in PT, and with high density of degranulated MCs-Try in $\mathrm{T}(\mathrm{p}=0.0289)$, also confirmed by ultrastructural analysis.

Conclusions: This preliminary investigation suggest that during breast cancer progression the MCs may contribute to stromal remodelling and differentiation of myofibroblasts, through tryptase released in stromal microenvironment. 


\section{Introduction}

The fibroblasts are the non-vascular, non-epithelial and non-inflammatory cells of the connective tissue, ${ }^{1}$ and they represent its principal cellular component.

They are embedded within the fibrillar matrix of the connective tissue and are, to a large extent, responsible for its synthesis. Normal stroma in most organs contains a minimal number of fibroblasts in association with a physiological extra-cellular matrix (ECM). ${ }^{2}$

The stromal microenvironment of many human tumors is fundamentally different from the stroma of the corresponding normal tissue.

It has been long known that a significant fraction of the stroma in some cancers consists of fibroblasts and in breast carcinomas, about $80 \%$ of stromal fibroblasts are thought to acquire a modified phenotype, similar to fibroblasts associated with wound healing. ${ }^{3}$ Moreover, many solid tumours are typically characterized by an increased deposition of dense collagenous stroma, termed "desmoplasia" and by the proliferation of reactive fibroblasts. ${ }^{4}$

In cancer, these activated fibroblasts, also termed myofibroblasts or carcinoma-associated fibroblasts, are morphologically characterized by large spindle-shaped cells with smooth muscle phenotypic properties, ${ }^{5}$ and commonly identified by their expression of $\alpha$-smooth-muscle actin $(\alpha$ SMA). ${ }^{2,6}$ Nevertheless, the list of $\alpha-\mathrm{SMA}^{+}$spindled cells may be harder to identify immunohistochemically and the electron microscopy can offer a more confident interpretation of myofibroblastic differentiation in a pathological context. ${ }^{7}$

Myofibroblasts play a central role in the complex process of tumour-stroma interaction, and consequently, growing evidence suggests that they promote tumorigenesis, neoplastic progression, angiogenesis and metastasis, compared with fibroblasts obtained from non-neoplastic locations.

Although there is agreement on myofibroblast disappearance from a normally healing wound by apoptosis, a topic of extensive investigation and discussion is the origin of myofibroblasts. These elements can apparently derive from several different sources: the most frequent proposed hypothesis is recruitment from local resident fibroblasts and, less commonly, smooth muscle cells, pericytes, 
endothelial cells, bone-marrow-derived circulating fibrocytes and epithelial-to-mesenchymal transformation-derived cells and the activating factors involved could be various. ${ }^{8-11}$

It has been established that mast cells (MCs) exert powerful effects on fibroblasts ${ }^{12,13}$ and in particular, the tryptase, a trypsin-like serine proteinase which selectively concentrates in secretory granules of human MCs, is a potent mitogen in vitro ${ }^{14-16}$ and it stimulates collagen synthesis in human lung and dermal fibroblasts. ${ }^{16-18}$

MCs represent a group of bone marrow-derived granulocytes in the innate immune system and, after leaving the vascular bed, they are early recruited to, and activated in the microenvironment of a developing tumour. MCs functionally matured contain a variety of mediators, such as multifunctional cytokines, histamine, and proteinase.

We identified immunohistochemically the presence and distribution of $\alpha-\mathrm{SMA}^{+}$and $\mathrm{CD} 34^{+}$ fibroblasts in the stroma of the primary tumour $(\mathrm{T})$, contiguous peri-tumoral (PT) and distant non-tumoral tissues (NT) from each breast carcinoma. Given the possible uncertainty in the myofibroblast identification by immunohistochemistry, we performed an ultrastructural analysis. Moreover, in the same compartments, we examined the density of both MCs stained histochemically with toluidine blue (TB) (MCs-TB) and immunolabeled for tryptase (MCs-Try), in order to assess if there are significant differences related to different histological compartments, and simultaneous interaction with fibroblasts in invasive human breast cancers. 


\section{Materials and methods}

\section{PATIENT TISSUES}

Thirty tissue samples from a consecutive series of patients with diagnosis of primary breast cancer were used in this study.

Before undergoing routine surgery, all patients signed an informed consent form authorizing the Institute to utilize their removed biological tissues for research purposes. Just after surgical removal of breast tumors, the pathologist macroscopically selected samples from the primary tumour $(\mathrm{T})$, contiguous peri-tumoral (PT) and distant non-tumoral (NT) breast tissue. Successively, each sample from each tissue compartment was divided in two symmetrical pieces intended for immunohistochemical and ultrastructural analyses.

The clinicopathological characteristics of the tumours are summarized in Table 1.

Specimens were examined at the Department of Pathology of our Institute and were classified as follows: invasive ductal carcinoma (IDC) not otherwise specified (NOS) ( $n=26)$, invasive lobular carcinoma (ILC) $(n=3)$ and invasive cribriform carcinoma (ICC) $(n=1)$ on the basis of histological examination. Four invasive tumours were associated with more than $25 \%$ of carcinoma in situ (CIS). The median age of the patients was 52 years (range 32-75 years) and was normally distributed.

For the tumour size classification the following criteria has been utilized: T1 tumour $2 \mathrm{~cm}$ or less in greatest dimension $(\mathrm{n}=18)$; T2 tumour more than $2 \mathrm{~cm}$ but not more than $5 \mathrm{~cm}$ in greatest dimension, and T4 tumour of any size with direct extension to the chest wall or skin $(n=12)$. Axillary lymph node status was positive in $45 \%(n=13)$ and negative in $55 \%(n=16)$ of patients. Histological grade was performed according to the Elston and Ellis method. ${ }^{19}$

Estrogen receptor $(\mathrm{ER})$ and progesterone receptor $(\mathrm{PgR})$ status were previously immunohistochemically assessed and the tumours were categorized as positive or negative according to the cut-off of $10 \%$ of positive immunostained cells (negative $\leq 10 \%$ and positive $>10 \%$ ). Tumour proliferative activity was determined as the percentage of tumour cells expressing the growth-related MIB-1 antigen (negative $\leq 20 \%$ and positive $>20 \%$ of positive immunostained cells). ${ }^{20}$ 


\section{IMMUNOHISTOCHEMISTRY FOR STROMAL FIBROBLASTS}

Formalin-fixed and paraffin-embedded tissues were cut into $4 \mu \mathrm{m}$ thick consecutive sections and for each specimen, the first section was stained with hematoxylin and eosin for routine morphologic examination, and others were processed for immunohistochemistry as previously described. ${ }^{21}$ Briefly, sections were deparaffinized with xylene, rehydrated in graded ethanol solutions, 1x phosphate-buffered saline (PBS) and subjected to heating pretreatment in order to enhance antigen retrieval. Tissue slides were then incubated with two murine monoclonal antibodies against $\alpha$-SMA (clone B4; Santa Cruz, California, USA) (1:150 dilution in PBS) and CD34 (clone QBEnd10; Novocastra Laboratories Ltd, Newcastle, UK) (1:50 dilution in PBS), overnight at $4^{\circ} \mathrm{C}$. Specimens were then incubated with biotinylated antimouse $\operatorname{IgG}$ for $30 \mathrm{~min}$, followed by peroxidase-labelled streptavidin for $30 \mathrm{~min}$, bound antibodies were visualized with 3-amino-9-ethylcarbazole substrate-chromogen (Labelled streptavidin-Biotin2 System-Horseradish Peroxidase; DakoCytomation, Glostrup, Denmark) for $15 \mathrm{~min}$ in the dark and counterstained with Mayer's haematoxylin. As a positive internal control we used the staining of blood vessels for the cellular marker CD34 and the staining of normal myoepithelial cells for the antigen $\alpha$-SMA. For negative controls, the primary antibody was omitted and replaced by PBS.

Two independent observers scored $\alpha$-SMA and CD34 immunostaining and evaluated as percentage of immunoreactive stromal cells with respect to the total analyzed, in three different microscopic fields at 400X in each breast specimen.

To analyze density and morphological distribution of MCs in the various compartments, every serial section adjacent to that stained for stromal fibroblasts were immunostained for MC tryptase and histochemically stained with TB.

A mouse monoclonal antibody directed against human mast cell tryptase (clone G3; Chemicon International, Temecula, CA, USA) $(0.5 \mu \mathrm{g} / \mathrm{mL}$ concentration in PBS $)$ and the 3-amino-9-ethylcarbazole as chromogen were used to evidence immunohistochemically intact as well as degranulated MCs-Try following the standard procedure above reported. A section of breast cancer with extensive infiltration by MCs noted on routine histological examination served as positive control and, replacing primary antibody 
with PBS, also as negative control. Photomicrographs were acquired under bright field illumination with a Leica DMLB optical microscope (Leica, Cambridge, UK) and analyzed with Leica IM1000 software. Immunohistochemical analysis was based on appearance of MCs-Try in the stroma and classified as intact and degranulated. The intact MCs-Try showed red stained homogeneous cytoplasm, whereas the degranulated MCs-Try appeared as disrupted cells with a cytoplasmic weak staining not homogeneous and pericellular, scattered in connective tissue.

Every fourth serial section was histochemically stained with a $1 \%$ aqueous solution of TB (Merck, Darmstadt, Germany) for $3 \mathrm{~min}$ and then rinsed with distillated water, to highlight intact metachromatic MCs with heparin-rich intracellular granules and identifiable by their dark purple granules.

MCs-Try and MCs-TB were counted in six to eight, non-overlapping 200X microscopic fields by two independent investigators, covering both peripheral and central regions (core) of each section. Areas of adipose tissue were also excluded due to its low number of mast cells. Cells showing an equivocal staining or lacking a nucleus were not counted.

MCs density in every T, PT and NT histological section was evaluated as median (interval of variation).

\section{ULTRASTRUCTURAL ANALYSIS}

Among the above cases, ten samples including the T, PT and NT tissue compartment, were also analyzed by conventional transmission electron microscopy, in order to study ultrastructurally the myofibroblast component and to identify MCs in breast cancer. For this purpose, the symmetrical sample of each tissue compartment, adjacent to that utilized for immunohistochemical studies, was finely cut into small pieces and fixed in glutaraldeide $2.5 \%$ in $0.1 \mathrm{M} \mathrm{PBS}$ (phosphate buffer), for $4 \mathrm{hr}$ at $4{ }^{\circ} \mathrm{C}$ and then postfixed in $1 \%$ osmium tetroxide in PBS, for 20 min at $4^{\circ} \mathrm{C}$. Fixed samples were extensively washed in PBS, dehydrated in graded alcohols and propylene oxide and, finally, embedded in Epon-Araldite (Taab, Redding, UK). The $2 \mu \mathrm{m}$ thick semi-thin sections were heat stained with periodic acid-Schiff and TB-borax.

Ultrathin sections for electron microscopy study were mounted on formvar-coated nickel grids, stained with uranyl acetate, lead citrate, and observed with a transmission electron microscope Morgagni 268 (FEI Company, Italy). 


\section{STATISTICAL ANALYSIS}

Data were analyzed with two-tailed non-parametric Kruskall-Wallis and Mann-Whitney tests. Statistical significance was calculated for a 95\% confidence interval $(p<0.05)$. The statistical analyses were performed using Prism 5.00 software package (GraphPad Software, San Diego, CA, USA). 


\section{Results}

\section{FIBROBLAST DENSITY}

Neither the lobular nor the extralobular stroma of tumour-free breast tissues showed $\alpha$-SMA ${ }^{+}$fibroblasts (Figure 1A). In normal and peri-tumoral breast tissues, $\alpha$-SMA expression was detected in myoepithelia as a continuous layer around ductal and acinar basement (Figure 1A,B). However, $\alpha$-SMA reactivity was detected also in the wall of stromal muscularized vessels. Fibroblast reactivity for $\alpha$-SMA were not observed in PT breast tissues except $8(27 \%)$ cases with positive myofibroblasts in the stroma. By contrast, each of the 30 invasive tumours showed $\alpha$-SMA reactivity and presented distinct myofibroblasts in connective tissue (Figure 1C).

Figure 2 shows tissue density of $\alpha$-SMA and CD34 immunoreactive fibroblasts on the first two adjacent tissue sections of NT, PT and T compartment of the same tumour.

A stronger and more distinct fibroblast reactivity for $\alpha$-SMA was observed in breast T compartment compared to PT and NT tissues [67.5 (44.9-84), 0.0 (0-64.9), 0.0 (0-0), respectively] (Figure 2A), and the comparison of the median distribution revealed statistically significant differences between the three compartments $(\mathrm{p}<0.0001$, by 1way ANOVA test). The intergroup comparisons showed that the median number of $\alpha-\mathrm{SMA}^{+}$fibroblasts was statistically higher in T than PT breast tissues (PT vs. T, p $<0.0001$, by Mann Whitney test).

$\mathrm{CD}^{+}{ }^{+}$fibroblasts were prevalently within intralobular stroma of histologically normal glands, all characterized by a uniform pattern of staining (Figure 1D). CD34 immunoreactivity was also detected in the wall of small and medium calibre blood vessels within stroma of all examined specimens and these vessels were easily distinguishable from the fibroblasts. PT tissues exhibited a distribution of CD34 fibroblasts similar to the NT compartment, with stromal fibroblasts around ductal and lobular units (Figure 1E). Moreover, contemporaneously to consistent enhance of $\alpha$-SMA expression, the stroma of T tissues was devoid of $\mathrm{CD}^{+} 4^{+}$fibroblasts, with the exception of 4 (13\%) tumours (2 IDC and 2 ILC) with a focal CD34 positivity in extralobular fibroblasts $(25.3 \%, 26.7 \%, 24.2 \%$ and $50.9 \%$ of positive cells, respectively) (Figure 1F). 
A higher density of stromal CD34 $4^{+}$fibroblasts was observed in all $30 \mathrm{NT}$ and PT than T tissues [83.2 (57.6-96.4) vs. 76 (0-91.8) vs. 0 (0-50.9), respectively], and the comparison between the three compartments varied significantly $(\mathrm{p}<0.0001)$ (Figure $2 B)$. The intergroup comparisons showed that the median number of CD34 ${ }^{+}$fibroblasts was statistically higher in NT and PT than in T breast tissues (NT vs. PT, $\mathrm{p}=0.0228$; NT vs. T, and PT vs. T, both $\mathrm{p}<0.0001)$.

\section{MAST CELLS DENSITY}

Each breast lesion contained MCs in a variable quantity and the infiltration of both MCs-TB and MCsTry was present already in the uninvolved breast compartment of each sample, distributed in the stroma of normal duct-lobular units (Figure $1 \mathrm{G}, \mathrm{J})$.

MCs-TB were located mostly in the connective stroma, in the interface between growing tumours and healthy breast tissue and, very often, in tight association with small blood vessels within tumour microenvironment (Figure 1H). Interestingly, utilizing tryptase immunolabelling, we observed MCs-Try not only at the boundary between $\mathrm{T}$ and NT tissue around small calibre blood vessels (Figure 1K), but also within the core of the invasive tumours and foci of micro invasion of tumour mass (Figure 1L).

Densities of MCs-TB and MCs-Try on NT, PT and T compartments of the same breast tumour are summarized in Figure 2.

The total number of intact MCs-TB increased gradually from NT, to adjacent PT and T tissues [13.7 (7.524.7), 25.0 (6-47.3) and 32.8 (8-72.9), respectively] and the comparison between the three compartments varied significantly $(\mathrm{p}<0.0001)$. The median number of MCs-TB was statistically higher in T and PT than in NT breast tissues (NT vs. PT, and NT vs. T, both $\mathrm{p}<0.0001$; PT vs. T, $\mathrm{p}=0.0011$ ) (Figure $2 \mathrm{C}$ ).

Similarly, the count of intact MCs-Try increased progressively from NT, to adjacent PT and T tissues [3.2 (0.3-7.3), $7.7(2.0-28.7)$ and 34.3 (15.5-94.4), respectively] and there was a statistically significant difference comparing the three compartments $(\mathrm{p}<0.0001)$. The median number of intact MCs-Try was significantly higher in PT than in NT, and still higher in T than in NT breast tissues (NT vs. PT, NT vs. T, and PT vs. T, all p<0.0001) (Figure 2D). 
The increase from PT towards T tissues was more evident in MCs-Try than MCs-TB (7.7 vs. 34.3, $\mathrm{p}<0.0001$, in MCs-Try; 25 vs. 32.8, $\mathrm{p}=0.0011$, in MCs-TB). Comparing the two MC populations, median number of the intact MCs-TB was greater than intact MCs-Try in PT and adjacent NT compartments (13.7 vs. 3.2 and 25 vs. 7.7, respectively); in T, the median density of MCs-Try was higher than MCs-TB, but not statistically significant (34.3 vs. 32.8 , respectively).

The density of degranulated MCs-Try considerably decreased from NT, towards adjacent PT and T tissues [79.5 (59.3-97.7), 70.4 (38.5-90.4) and 36.1 (22.8-74.7), respectively] and the comparison of median distribution between the three compartments revealed statistically significant differences $(\mathrm{p}<0.0001)$. Comparing groups two by two, we showed that the degranulated MCs were present more significantly in NT and in adjacent PT tissues than T ones (NT vs. T and PT vs. T, p $<0.0001$; NT vs. PT, $\mathrm{p}=0.0002)($ Figure 2E).

\section{ASSOCIATION BETWEEN FIBROBLAST DENSITY AND MAST CELL DENSITY}

Table 2 shows the associations of $\mathrm{CD}^{+} 4^{+}$and $\alpha-\mathrm{SMA}^{+}$fibroblasts with MCs density in distant NT, adjacent PT and T tissues. In the distant NT, CD34 ${ }^{+}$fibroblasts correlated significantly to low density both of MCs-TB and intact MCs-Try ( $p=0.0346$ and $\mathrm{p}=0.0409$, respectively). In $\mathrm{T}$ tissues, the few preserved $\mathrm{CD} 34^{+}$fibroblasts were associated with low-density degranulated MCs-Try $(\mathrm{p}=0.0173)$.

The $\alpha$-SMA reactive fibroblasts significantly correlated with high-density of intact MCs-Try in PT compartment, and with high density of degranulated MCs-Try in T tissues $(\mathrm{p}=0.0289)$.

\section{ULTRASTRUCTURAL FINDINGS}

The presence of $\alpha$-SMA ${ }^{+}$fibroblasts was further confirmed by electron microscopic analyses, performed on ten tissue samples including the T, PT and NT tissue compartment.

Ultrastructural examination showed that the spindled cells exhibited myofibroblastic differentiation and were observed prevalently in $\mathrm{T}$ samples (Figure 3A). These cells showed a highly elongated shape, characterized by an oval nucleus to a pole of the cell with electron-dense clumped chromatin. Myofibroblasts were identified by cytoplasmic well-developed organelles, such as clusters of 
mitochondria located in a perinuclear position, the prominent rough endoplasmic reticulum along cytoplasmic axis and contractile myofilaments of smooth-muscle cells under the plasmal membrane. In addition, myofibroblasts contained the cell-to-matrix junction, known as the fibronexus, near cellular membrane. In ultrastructural terms, myofibroblasts were noticeably different from normal fibroblasts detected in NT, because they are devoid of the myofilaments and fibronexus, and from pericytes, for their exclusive location next to endothelial cells and for the presence of lamina.

In all $\mathrm{T}$ cases examined, there was a very tight contiguity between elongated cytoplasm of myofibroblast and neoplastic cells of the invasive front. The most surprising finding of our study is the relatively large numbers of elongated myofibroblasts in close apposition to interstitial cells with different types of cytoplasmic electron-dense granules greatly attributable to mast cells (Figure 3B).

Mast cells have been identified electronmicroscopically in all compartments of the breast samples analyzed. The criteria utilized for distinguishing mast cells from other similar elements, as basophiles, were: the presence of unilobular nucleus in the middle of the cell; the presence of microvillous processes, in the form of long and filiform cytoplasmic protrusions that departed from the surface of mast cells; and, the intracytoplasmic granules of $700 \mathrm{~nm}$ in diameter, tied up to membrane and with intragranular inclusions of variable form and structure. 


\section{Discussion}

It has been generally recognized the importance of tumour microenvironment during cancer initiation and progression since the definition of "seed and soil" hypothesis proposed by Paget in 1889. Two classical morphological evidences of the strong influence of stroma on many tumoral steps are desmoplasia, consisting of highly proliferative fibroblasts-like cells associated with an excessive deposit of ECM, and local inflammation, characterized by the infiltration of lymphocytes, macrophages, dendritic cells and MCs.

The study of Kankkunen et $a l .^{22}$ showed a significant increase in the number of MCs with tryptase activity in malignant breast carcinoma with respect to benign breast lesion and, however, Kashiwase et $a l{ }^{23}$ reported differences in the density of MCs among malignant breast tissues and adjacent healthy tissues from a single patient. Moreover, to date, reports investigating the distribution of $\alpha$-SMA reactive myofibroblasts associated with the analysis of MCs density in normal, adjacent peri-tumour and malignant breast tissue from the same patient, have not been published yet.

Our study has demonstrated that MCs infiltrated the connective stroma of the breast tissue since the early steps of cancerogenesis, then progressively increased in peri-tumoral fibrous tissue and further increased significantly around and within the invasive carcinoma. We showed that within the breast tumour microenvironment MCs represented an early and persistent infiltrating immune cell type. Both MCs-Try and MCs-TB infiltrated abundantly in the stroma at the site of tumour growth and, with lower density, MCs-Try accumulated also in the internal tumour field. In particular, we observed degranulant MCs-Try concentrated in the invasion fields, where both tumour and non involved epithelial component were present, as to oppose and limit cancer cell migration. We hypothesize that peripheral degranulated MCsTry, with respect to intact MCs-Try infiltrating mainly in the tumoral body, could play a detrimental role to the cancer cells and might participate in tumour rejection by several cytokines and proteolytic enzymes, including tryptase. As evidenced by previous works, ${ }^{24,25}$ connective tissue MCs can promote a beneficial effect on cancer through selective secretion of mitogenic and trophic factors without degranulation, or alternatively, the total granule release during $\mathrm{MC}$ degranulation would result in a detrimental effect to the tumour. 
On the basis of our results, it seems that MCs, and in particular MCs-Try, might play a positive protecting role against the tumour progression. Tryptase released by MCs in the stroma of distant normal mammary tissue, thanks to their natural inhibitors and normal tissue homeostasis, maintains a proteolytic balance. Nevertheless, during cancer progression, this balance is gradually disturbed in the benign breast lesions and definitively broken in the invasive carcinoma by overexpression of several proteases. ${ }^{26}$

Concurrently with a local increase in the number of tissue MCs, the appearance of activated myofibroblasts takes place. ${ }^{27}$ Numerous mediators produced by MCs are able to directly influence some of the fibroblast and myofibroblast biochemical-functional properties. Tryptase, for example, a serine protease unique to MCs, acquires the ability to remodel tissues, disrupting surrounding ECM and then induce stromal fibroblast proliferation and myofibroblast differentiation. In this microenvironment, experimental evidences have demonstrated that tryptase can stimulate fibroblast proliferation ${ }^{14-16}$ and collagen synthesis, ${ }^{16-18}$ can induce normal dermal human fibroblasts to express $\alpha$-SMA and contract collagen, ${ }^{28,29}$ and to deposite and remodel ECM. ${ }^{18}$

We observed that, in parallel to MCs increase, the $\alpha-\mathrm{SMA}^{+}$fibroblasts increased in step with tumour progression. Transition between distant NT, adjacent PT and invasive $\mathrm{T}$ was marked by increasing reactive myofibroblasts and slow disappearance of $\mathrm{CD} 34^{+}$stromal cells.

We also found that $\mathrm{CD} 34^{+}$fibroblasts are significantly associated to tissues with a low density of MCsTry, and in particular, the preserved $\mathrm{CD}^{+} 4^{+}$stromal cell population fibroblasts in invasive carcinomas were negatively correlated with degranulated MCs-Try. At the same time, the subsequent gain of $\alpha$-SMA expression in carcinoma-associated stroma is accompanied by increased infiltration of MCs, in fact in contiguous PT compartment, the $\alpha$-SMA reactive fibroblasts were strongly related with a high number of MCs-Try.

Thus, our findings, together with previous studies, ${ }^{4,30-33}$ suggest that the presence of $\alpha-\mathrm{SMA}^{+}$ fibroblasts in invasive breast cancers is associated with the absence of CD34 $4^{+}$stromal elements. In this respect, we could assume that this indicates malignancy in most cases, similarly to Ramaswamy et al. ${ }^{34}$ and Kuroda et $a l^{31}$ 
On the other hand, we found that $\mathrm{CD} 4^{+}$fibroblasts are present in $13 \%$ of invasive carcinomas, in particular, in two of three total ILCs. Therefore, we suggest that in contrast with invasive ductal carcinomas, disappearance of CD34 stromal immunoreactivity in invasive lobular carcinomas occurs gradually and that the loss of $\mathrm{CD}^{+} 4^{+}$fibrocytes as a single histological criterion might not suffice to support malignancy. In line with our findings, recent evidences indicate that loss of CD34 $4^{+}$fibrocytes is not a consistent feature in the stroma of all carcinomas; in fact, Nakayama et al. both in some pulmonary adenocarcinoma lesions ${ }^{35}$ and in diffuse type gastric carcinomas, ${ }^{36}$ and Ebrahimsade et al. ${ }^{37}$ in ILCs of the breast reported that $\mathrm{CD} 34^{+}$stromal expression was completely preserved.

Our analysis showed that elements with ultrastrtuctural characteristics of myofibroblasts were detected only in $\mathrm{T}$ tissue. Diagnosis of myofibroblast was strictly performed according to criteria elaborated by Eyden $^{7}$ and differentiated from fibroblast, myocyte, and pericyte. Such elements seem to be spatially correlated with neoplastic cells, MC and other mesenchymal elements, in reason of their hypothesized role in transformation of peritumoral connettive. ${ }^{7}$

We propose that, in the context of developing tumours, infiltrating MCs alter the surrounding microenvironment through its several proteases and MCs-Try might influence down regulation of CD34 and up regulation of $\alpha$-SMA in the tumour stromal fibroblasts. The process of acquisition of the myofibroblast phenotype is not indicative of malignancy in the breast, accordingly with Chauhan et al. ${ }^{33}$ and is probably linked to tryptase-induced stromal damage and subsequent attempt of stromal remodelling.

In conclusion, our preliminary data suggest that during breast cancer progression the MCs may contribute to stromal remodelling characterized by the phenotypic shift from the $\mathrm{CD}_{3} 4^{+} / \alpha-\mathrm{SMA}^{-}$ fibroblasts towards $\mathrm{CD}^{2} \% / \alpha-\mathrm{SMA}^{+}$myofibroblasts, through tryptase released in stromal microenvironment, in synergy with other granule-associated mediators. 
Acknowledgements

We thank Mr C. Salvatore for technical assistance.

\section{Competing interests}

The authors declare that no competing interests exist. 


\section{References}

1. Tarin D, Croft CB. Ultrastructural features of wound healing in mouse skin. J Anat. 1969; 105; 189-190.

2. Rønnov-Jessen L, Petersen OW, Bissell MJ. Cellular changes involved in conversion of normal to malignant breast: importance of the stromal reaction. Physiol Rev. 1996; 76; 69-125.

3. Sappino AP, Skalli O, Jackson B, Schürch W, Gabbiani G. Smooth-muscle differentiation in stromal cells of malignant and non-malignant breast tissues. Int J Cancer 1988; 41; 707-712.

4. Nakayama H, Enzan H, Miyazaki E, Kuroda N, Naruse K, Hiroi M. Differential expression of CD34 in normal colorectal tissue, peritumoral inflammatory tissue, and tumour stroma. $J$ Clin Pathol. 2000; 53; 626-629.

5. Lazard D, Sastre X, Frid MG, Glukhova MA, Thiery JP, Koteliansky VE. Expression of smooth muscle-specific proteins in myoepithelium and stromal myofibroblasts of normal and malignant human breast tissue. Proc Natl Acad Sci U S A 1993; 90; 999-1003.

6. Gabbiani G. The myofibroblast in wound healing and fibrocontractive diseases. J Pathol. 2003; 200; 500-503.

7. Eyden B, Banerjee SS, Shenjere P, Fisher C. The myofibroblast and its tumours. J Clin Pathol. $2009 ; 62 ; 236-249$.

8. Schürch W, Seemayer TA, Hinz B, et al. Myofibroblast. In: Mills SE, ed. Histology for pathologists, 3rd edn. Philadelphia, PA: Lippincott, Williams \& Wilkins, 2007:123-164.

9. Rønnov-Jessen L, Petersen OW, Koteliansky VE, Bissell MJ. The origin of the myofibroblasts in breast cancer. Recapitulation of tumor environment in culture unravels diversity and implicates converted fibroblasts and recruited smooth muscle cells. J Clin Invest. 1995; 95; 859-873.

10. Zeisberg EM, Tarnavski O, Zeisberg M et al. Endothelial-to-mesenchymal transition contributes to cardiac fibrosis. Nat Med. 2007; 13; 952-961.

11. Direkze NC, Hodivala-Dilke K, Jeffery R et al. Bone marrow contribution to tumor-associated myofibroblasts and fibroblasts. Cancer Res. 2004; 64; 8492-8495. 
12. Coussens LM, Raymond WW, Bergers G et al. Inflammatory mast cells up-regulate angiogenesis during squamous epithelial carcinogenesis. Genes Dev. 1999; 13; 1382-1397.

13. Frungieri MB, Weidinger S, Meineke V, Köhn FM, Mayerhofer A. Proliferative action of mastcell tryptase is mediated by PAR2, COX2, prostaglandins, and PPARgamma : Possible relevance to human fibrotic disorders. Proc Natl Acad Sci U S A 2002; 99; 15072-15077.

14. Ruoss SJ, Hartmann T, Caughey GH. Mast cell tryptase is a mitogen for cultured fibroblasts. $J$ Clin Invest. 1991; 88; 493-499.

15. Hartmann T, Ruoss SJ, Raymond WW, Seuwen K, Caughey GH. Human tryptase as a potent, cell-specific mitogen: role of signaling pathways in synergistic responses. Am J Physiol. 1992; 262; L528-534.

16. Abe M, Kurosawa M, Ishikawa O, Miyachi Y, Kido H. Mast cell tryptase stimulates both human dermal fibroblast proliferation and type I collagen production. Clin Exp Allergy 1998; 28; 1509 1517.

17. Cairns JA, Walls AF. Mast cell tryptase stimulates the synthesis of type I collagen in human lung fibroblasts. J Clin Invest. 1997; 99; 1313-1321.

18. Gruber BL, Kew RR, Jelaska A et al. Human mast cells activate fibroblasts: tryptase is a fibrogenic factor stimulating collagen messenger ribonucleic acid synthesis and fibroblast chemotaxis. J Immunol. 1997; 158; 2310-2317.

19. Elston CW, Ellis IO. Pathological prognostic factors in breast cancer. I. The value of histological grade in breast cancer: experience from a large study with long-term follow-up. Histopathology $2002 ; 41 ; 151-153$.

20. Mangia A, Chiriatti A, Tommasi S et al. BRCA1 expression and molecular alterations in familial breast cancer. Histol Histopathol. 2009; 24; 69-76.

21. Mangia A, Chiriatti A, Bellizzi A et al. Biological role of NHERF1 protein expression in breast cancer. Histopathology 2009; 55; 600-608.

22. Kankkunen JP, Harvima IT, Naukkarinen A. Quantitative analysis of tryptase and chymase containing mast cells in benign and malignant breast lesions. Int J Cancer 1997; 72; 385-388. 
23. Kashiwase Y, Morioka J, Inamura H, Yoshizawa Y, Usui R, Kurosawa M. Quantitative analysis of mast cells in benign and malignant breast lesions. Immunohistochemical study on formalinfixed, paraffin-embedded tissues. Int Arch Allergy Immunol. 2004; 134; 199-205.

24. Zudaire E, Martínez A, Garayoa M et al. Adrenomedullin is a cross-talk molecule that regulates tumor and mast cell function during human carcinogenesis. Am J Pathol. 2006; 168; 280-291.

25. Theoharides TC, Conti P. Mast cells: the Jekyll and Hyde of tumor growth. Trends Immunol. $2004 ; 25 ; 235-241$.

26. Noël A, Jost M, Maquoi E. Matrix metalloproteinases at cancer tumor-host interface. Semin Cell Dev Biol. 2008; 19; 52-60.

27. Hebda PA, Collins MA, Tharp MD. Mast cell and myofibroblast in wound healing. Dermatol Clin. 1993; 11; 685-696.

28. Yamamoto T, Hartmann K, Eckes B, Krieg T. Mast cells enhance contraction of threedimensional collagen lattices by fibroblasts by cell-cell interaction: role of stem cell factor/c-kit. Immunology 2000; 99; 435-439.

29. Gailit J, Marchese MJ, Kew RR, Gruber BL. The differentiation and function of myofibroblasts is regulated by mast cell mediators. J Invest Dermatol. 2001; 117; 1113-1119.

30. Kuroda N, Toi M, Nakayama $\mathrm{H}$ et al. The distribution and role of myofibroblasts and CD34positive stromal cells in normal pancreas and various pancreatic lesions. Histol Histopathol. 2004; 19; 59-67.

31. Kuroda N, Jin YL, Hamauzu T et al. Consistent lack of CD34-positive stromal cells in the stroma of malignant breast lesions. Histol Histopathol. 2005; 20; 707-712.

32. Barth PJ, Ebrahimsade S, Ramaswamy A, Moll R. CD34+ fibrocytes in invasive ductal carcinoma, ductal carcinoma in situ, and benign breast lesions. Virchows Arch. 2002; 440; 298303.

33. Chauhan H, Abraham A, Phillips JR, Pringle JH, Walker RA, Jones JL. There is more than one kind of myofibroblast: analysis of CD34 expression in benign, in situ, and invasive breast lesions. J Clin Pathol. 2003; 56; 271-276. 
34. Ramaswamy A, Moll R, Barth PJ. CD34+ fibrocytes in tubular carcinomas and radial scars of the breast. Virchows Arch. 2003; 443; 536-540.

35. Nakayama H, Enzan H, Yamamoto $\mathrm{M}$ et al. CD34-positive stromal cells in primary lung carcinomas. Oncol Rep. 2003; 10; 1313-1316.

36. Nakayama H, Enzan H, Miyazaki E et al. CD34 positive stromal cells in gastric adenocarcinomas. J Clin Pathol. 2001; 54; 846-848.

37. Ebrahimsade S, Westhoff CC, Barth PJ. CD34+ fibrocytes are preserved in most invasive lobular carcinomas of the breast. Pathol Res Pract. 2007; 203; 695-698. 
Table 1. Clinicopathological characteristics of 30 primary breast cancers

\section{Variables}

$n$

$(\%)$

Age at diagnosis (years)

\begin{tabular}{lcc}
$\leq 52$ & 16 & $(53)$ \\
\hline$>52$ & 14 & (47)
\end{tabular}

Histological type

\begin{tabular}{lcc} 
IDC (NOS) & 26 & $(87)$ \\
\hline ILC & 3 & $(10)$ \\
\hline ICC & 1 & $(3)$
\end{tabular}

Invasive tumours associated with CIS ( $\geq 25 \%)$

\begin{tabular}{lll} 
IDC (NOS) & 2 & $(50)$ \\
\hline ILC & 1 & $(25)$ \\
\hline ICC & 1 & $(25)$
\end{tabular}

Tumour size $(\mathrm{cm})$

$\mathrm{T} 1$

18

$\mathrm{T} 2$ / T4

12

Nodal status

Negative

16

Positive

13

${ }^{\mathrm{a}} \mathrm{N}_{\mathrm{X}}$

Histological grade

\begin{tabular}{lcc} 
G1 & 3 & (10) \\
\hline G2 & 14 & $(47)$ \\
\hline G3 & 13 & $(43)$
\end{tabular}

ER

Negative

4

Positive

26

PgR

Negative 9

Positive

21

(70)

MIB-1

Negative

17

Positive

13

${ }^{\mathrm{a}} \mathrm{N}_{\mathrm{X}}=$ Regional lymph nodes cannot be assessed. 
Table 2. Associations between stromal fibroblasts and high or low mast cell density in breast cancer

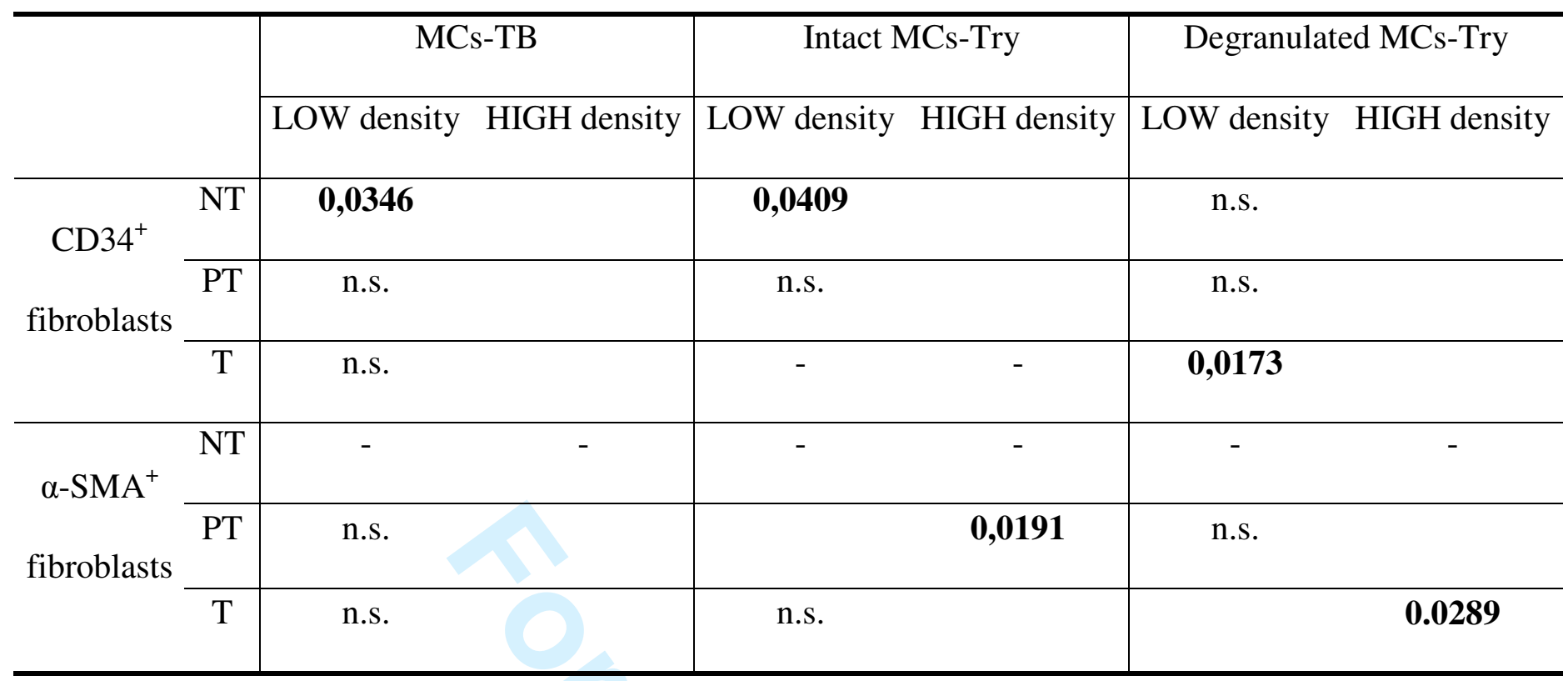

NT, distant non-tumoral tissue; PT, peri-tumoral tissue contiguous to tumour; T, primary breast tumour tissue. MCs-TB, toluidine blue-labeled mast cells; MCs-Try, tryptase-labeled mast cells. Statistical significance have been obtained by non-parametric analysis of variance and by Mann Whitney two unmatched groups test. 


\section{Figure legends}

Figure 1. Immunoreactivity for stromal fibroblasts and mast cells in breast cancer. Distant non-tumoral and contiguous peri-tumoral tissues show $\alpha-\mathrm{SMA}^{+}$smooth muscle cells of muscularized vessels $(\mathbf{A}, \mathbf{B})$ and $\alpha-\mathrm{SMA}^{+}$ myoepithelial cells of normal glandular (A) and compressed ducts (B). Small calibre vascular structures are $\mathrm{CD}_{4} 4^{+}(\mathbf{D}, \mathbf{F})$ and densely packed CD34 ${ }^{+}$fibroblasts encircle acinar and glandular structures of non-tumoral and peri-tumoral breast tissue (D,E). The stroma of invasive carcinoma contains $\alpha-\mathrm{SMA}^{+}$myofibroblasts $(\mathbf{C})$ and CD34- fibroblasts $(\mathbf{F})$. Mast cells toluidine blue-stained increased gradually from non-tumoral (G) and peritumoral tissues $(\mathbf{H})$ to tumour $(\mathbf{I})$, located in the connective stroma, in tight association with small blood vessels. In $\mathbf{J}-\mathbf{L}$ are shown intact (arrows) and degranulated tryptase ${ }^{+}$mast cells (arrowheads) ( $\times 200$ microscopic magnification). 
Figure 2. Distribution of reactive stromal fibroblasts and mast cells in the varoius tissue compartments of breast cancer. In $\mathbf{A}$ and $\mathbf{B}$, the distribution of $\alpha$-SMA and CD34 fibroblast reactive are represented; in $\mathbf{C}, \mathbf{D}$ and $\mathbf{E}$ the expression levels of toluidine blue-labeled, intact tryptase-immunoreactive and degranulated tryptaseimmunoreactive mast cells are shown, respectively. Values are expressed as the median (horizontal bold line in each box), with the $25^{\text {th }}$ and $75^{\text {th }}$ percentiles (interquartile range, top and bottom of each box) and the farthest points that are not outliers (top and bottom of each $\mathrm{T}^{\perp}$ bar). Dot indicates outliers. NT, distant non-tumoral breast tissue; PT, peri-tumoral tissue contiguous to breast tumour; T, primary breast tumour. ***, $p<0.001$; *, $p<0.05$. 
Figure 3. Electron photomicrograph of a stromal myofibroblast and mast cell in breast cancer. In A, a typical spindled cell with myofibroblastic differentiation in breast tumor sample showing cytoplasm with abundant organelles, protein bundles near plasmal membrane and the fibronexus (arrow). In B, cytoplasmic extensions of a tumor myofibroblast tightly closed to a cell with electrondense bodies corresponding to mast cell. The numerous secretory granules (arrowheads) typical of breast parenchyma mast cells can be better observed in $\mathbf{C}$, showing an enlargement of B. (Magnification: A, ×3500; B, ×5600; C, ×11000). 

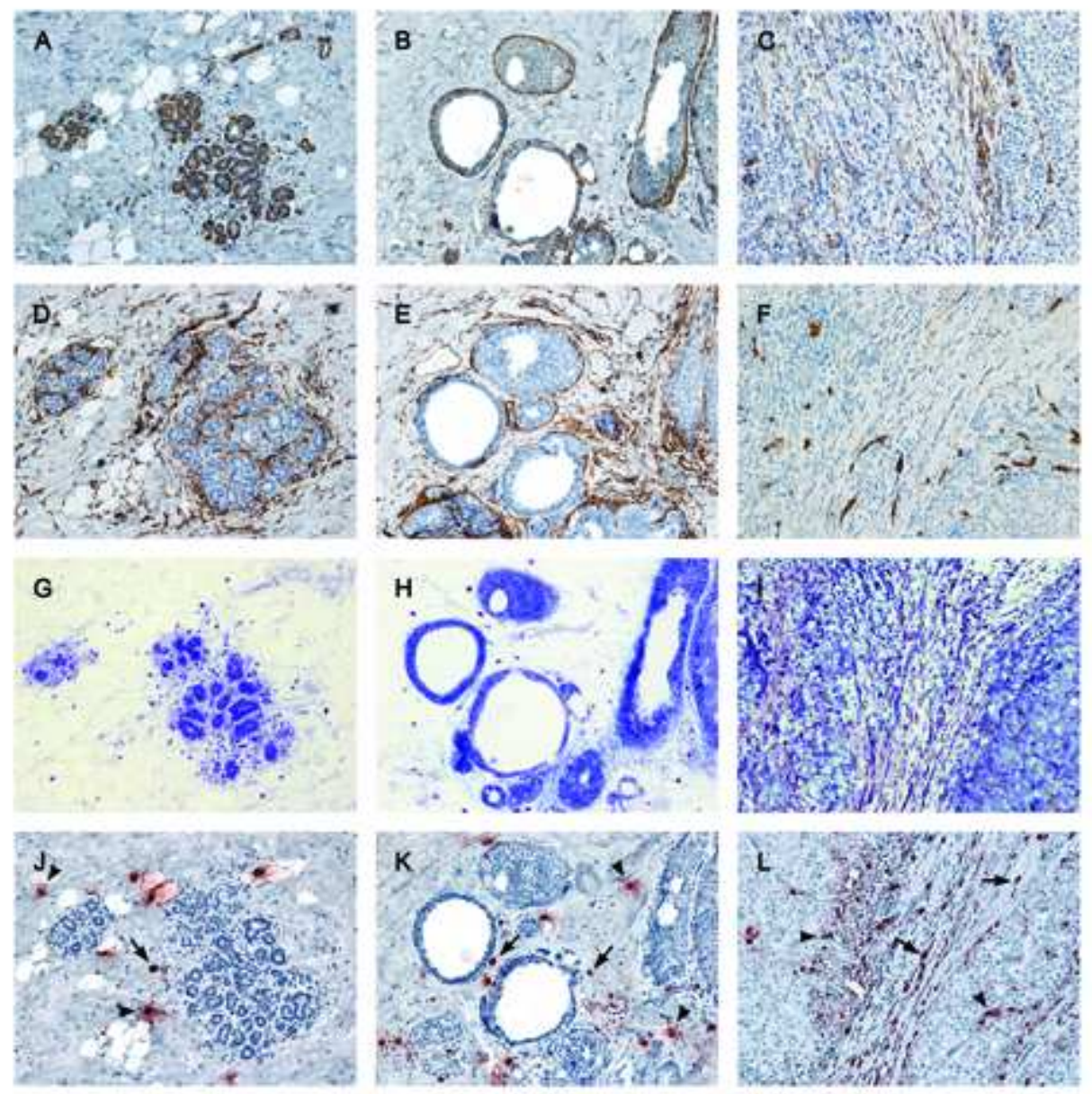

$20 \times 20 \mathrm{~mm}(600 \times 600 \mathrm{DPI})$ 

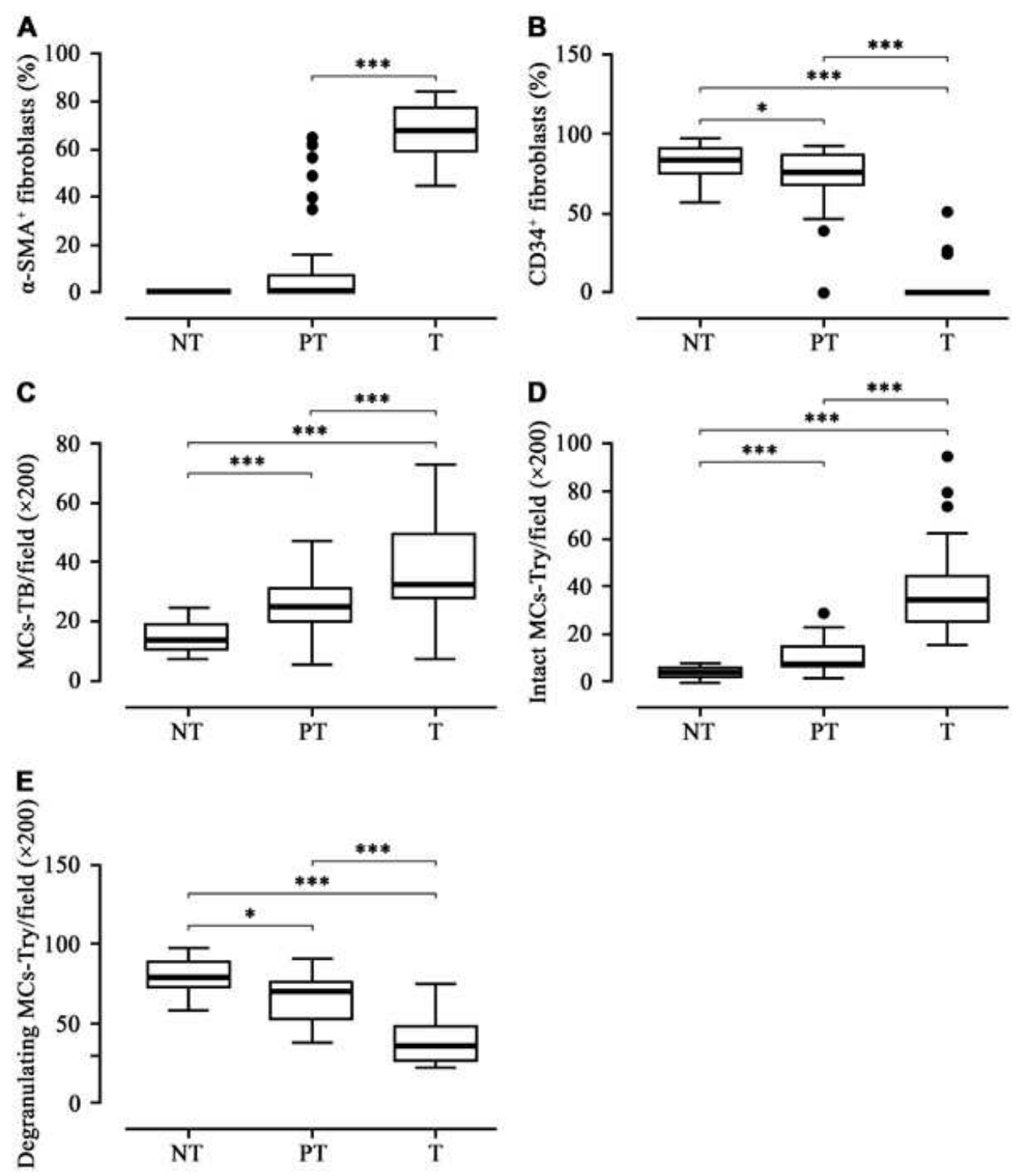

$53 \times 61 \mathrm{~mm}(300 \times 300$ DPI $)$ 


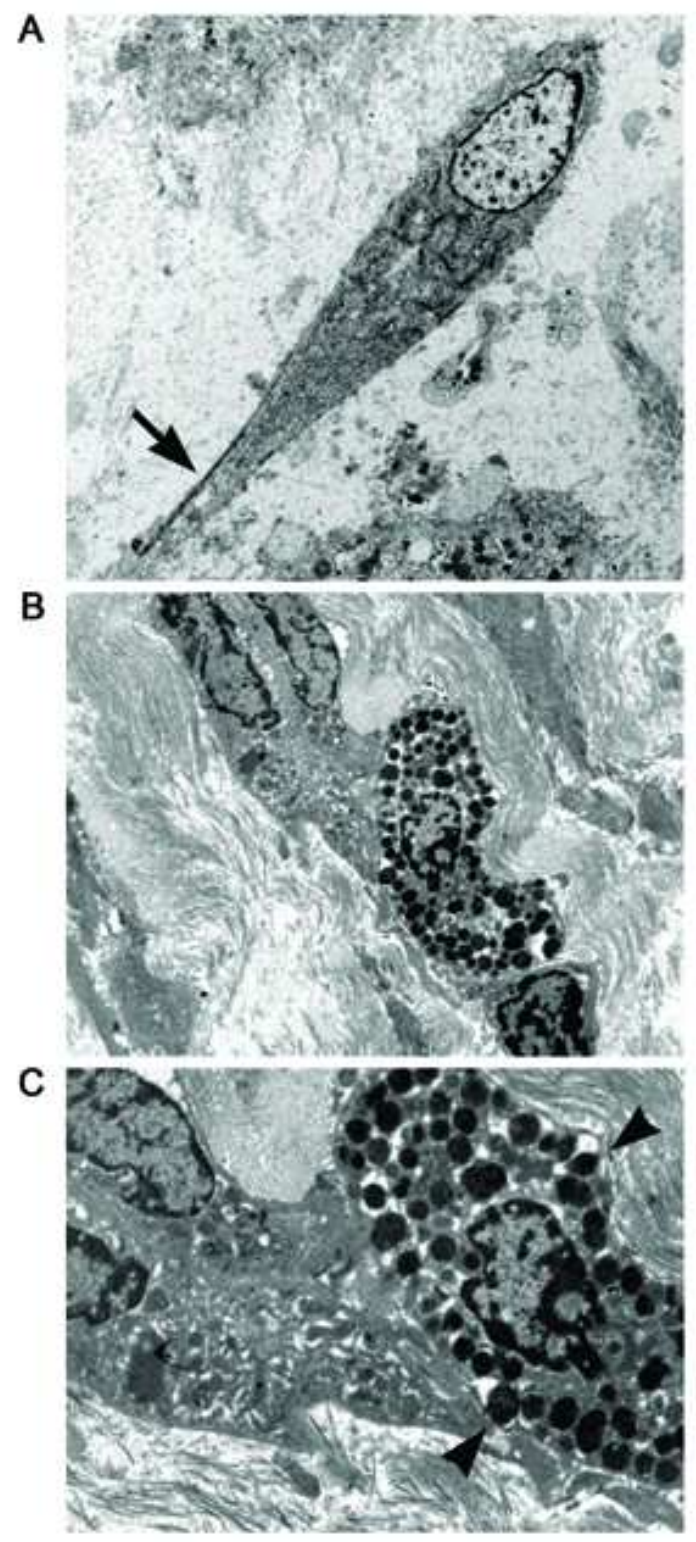

$12 \times 27 \mathrm{~mm}(600 \times 600$ DPI $)$ 
Secretary Office

Lab. Biology

Lab. Biochemistry

Tel./Fax: 0039/080/5555561

Tel.: 0039/080/5555527

Lab. Molecular
Tel.: 0039/080/5555530

Bari May 7, 2010

Editorial Office

Histopathology

Histopathology • Blackwell Publishing Ltd • 9600 Garsington Road • Oxford

Dear Editor,

here enclosed our manuscript "Tissue remodelling in breast cancer: human mast cell tryptase as an initiator of myofibroblast differentiation" that we would like to submit for publication in Histopathology. The present manuscript is an original unpublished work and is not being submitted in whole or in part elsewhere. All authors have agreed to the contents of the manuscript in its submitted form.

Thank you in advanced for your consideration.

Best regards

Anita Mangia

(address for correspondence)

Anita Mangia, $\mathrm{PhD}$.

Clinical Experimental Oncology Laboratory

National Cancer Centre

Via Samuel F. Hahnemann, 10

70126 Bari, Italy

Phone/Fax 0039-080-5555561

e-mail: a.mangia@oncologico.bari.it 